\title{
Procedimientos contables y su incidencia en la sistematización de la información de la Cooperativa de Ahorro y Crédito Atlántida de la ciudad de Cañar
}

\author{
Accounting procedures and their impact on the systematization of the \\ information of the Cooperative de Save y Credit Atlántida of the city of Cañar \\ Wilma Patricia Valdez Fajardo. ${ }^{1}$, Cecilia Ivonne Narváez Zurita. ${ }^{2}$, Jorge Edwin Ormaza Andrade. ${ }^{3}$, \\ \& Juan Carlos Erazo Álvarez. ${ }^{4}$
}

\section{DOI: https://doi.org/10.33262/visionariodigital.v3i2.1.586}

\begin{abstract}
.
Currently the political and economic scenario of Ecuador, is subject to constant and permanent changes in which financial institutions are immersed, these transformations require that every organization has procedures manuals to minimize risks and streamline accounting processes, thus admitting to plan, organize, execute, direct and control their financial intermediation activities quickly, thus promoting the efficient performance of human talent that comprise it. Under this context, it is proposed in this investigation to design a manual of accounting procedures that contributes to the improvement of the accounting and financial information in the Cooperative de Save y Crédit Atlántida of the city of Cañar, favoring in such a way to the entity in the elaboration, registry and control of the executed processes. The design of the article is non-experimental from a mixed approach; for the process of elaboration of the manual, initially a phase of revision of theoretical contributions referring to the topic was approached, followed by a stage of diagnosis and evaluation of the cooperative of savings and credit Atlantis, from the results obtained the manual was designed and described each one of its elements.
\end{abstract}

Keywords: Accounting procedures, financial statements, active, systematization.

\footnotetext{
${ }^{1}$ Universidad Católica de Cuenca, Posgradista Maestría en Contabilidad y Auditoría, Cuenca, Ecuador, wpvaldezf705@psg.ucacue.edu.ec

${ }^{2}$ Universidad Católica de Cuenca, Subdirección de Posgrado, Cuenca, Ecuador, inarvaez@ucacue.edu.ec

${ }^{3}$ Universidad Católica de Cuenca, Subdirección de Posgrado, Cuenca, Ecuador, jormaza@ucacue.edu.ec

${ }^{4}$ Universidad Católica de Cuenca, Subdirección de Posgrado, Cuenca, Ecuador, jcerazo@ucacue.edu.ec
} 


\section{Resumen}

Actualmente el escenario político y económico del Ecuador, está sujeto a cambios constantes y permanentes en el cual las entidades financieras se encuentran inmersas, estas trasformaciones exigen que toda organización cuente con manuales de procedimientos que permitan minimizar los riesgos y agilizar los procesos contables; admitiendo de esta manera planear, organizar, ejecutar, dirigir y controlar rápidamente sus actividades de intermediación financiera, promoviendo así el desempeño eficiente del talento humano que lo integran. Bajo este contexto, se propone en esta investigación diseñar un manual de procedimientos contables que contribuya al mejoramiento de la información contable y financiera en la Cooperativa de Ahorro y Crédito Atlántida de la ciudad de Cañar, favoreciendo de tal manera a la entidad en la elaboración, registro y control de los procesos ejecutados. El diseño del artículo es no experimental desde un enfoque mixto; para el proceso de elaboración del manual, inicialmente se abordó una fase de revisión de aporte teóricos referentes al tema, seguidamente se realizó una etapa de diagnóstico y evaluación de la cooperativa de ahorro y crédito Atlántida, a partir de los resultados obtenidos se diseñó el manual y describió cada uno de sus elementos.

Palabras clave: procedimientos contables, estados financieros, activo, sistematización.

\section{Introducción.}

En Latinoamérica y puntualmente en el Ecuador, las organizaciones empresariales habitualmente no valoran la importancia de tener manuales de procedimientos contables; así como también contar con sistemas de control interno; que les conduzca a la minimización de riesgos e insuficiencias contables, financieras y administrativas que se muestran en el desarrollo cotidiano de las actividades propias de la empresa. Toda empresa sea cual fuere el giro del negocio, su naturaleza, tamaño, o sector donde se desenvuelve requiere de procedimientos internos que salvaguarden las inversiones realizadas por los accionistas, directivos, socios o dueños de las empresas; así como también, poseer herramientas básicas que les permita controlar según las diferentes políticas establecidas por la organización, el cumplimiento de metas y objetivos por parte de la administración.

El manual de procedimientos contables es un elemento que forma parte del proceso administrativo, así como también del control interno, el mismo que conlleva a que la empresa cuente con información precisa, oportuna, detallada, ordenada y completa; donde se visualiza en forma exacta cada uno de los pasos, instrucciones, responsabilidades concernientes a las actividades de la empresa. Por lo tanto, el manual de procedimientos contables tiene una relación simbiótica con el control interno; la sinergia de estos dos elementos deben 
incorporarse en cada una de las acciones y actividades que realizan las empresas, esto conduce a que las organizaciones empresariales sean más eficientes en la toma de decisiones; en otras palabras las empresas que incorporen a sus actividades las herramientas antes descritas puedan contar con una adecuada gestión administrativa, contable y financiera.

Se considera al manual de procedimientos como una herramienta básica, elemental y positiva del control interno, el manual de procedimientos dentro de una organización es una guía práctica, donde se expresa, las políticas, procedimientos, controles; y, al disponer de este instrumento ayuda a disminuir los desaciertos tanto operativos como financieros, mostrando razonabilidad en los estados financieros; lo cual conduce a una toma de decisiones acertada. Por otra parte, el control interno asevera que la información contable sea fiable y enfrente de manera categórica a las estafas, dolos, malversación de fondos, actos de corrupción entre otros, dando una eficiencia operativa para elaborar las actividades.

La carencia de un manual de procedimientos contables provoca grandes problemas en el mundo de los negocios, como el desconocimiento de los deberes y responsabilidades que se dan en cada puesto de trabajo, incumplimiento de las normas y políticas que se deben manejar en las distintas actividades desarrolladas, lo que impide un retraso de los registros contables.

Por las consideraciones antes enunciadas, se plantea para el estudio investigativo el siguiente objetivo: diseñar un manual de procedimientos contables que permita el mejoramiento de la información contable y financiera en la Cooperativa de Ahorro y Crédito Atlántida de la ciudad de Cañar como herramienta base de control interno.

\section{Bases teóricas de la investigación.}

El análisis de las bases teóricas, tuvo como propósito fundamental delimitar teóricamente los conceptos planteados en la investigación; su desarrollo exigió integrar el conjunto de concepciones organizadas de manera lógica, sistemática y jerárquica.

\section{Fundamentación teórica del manual de procedimientos contables.}

La creación de manuales de procedimientos contables al interior de una empresa, constituye un documento de sustento y referencia para el talento humano de una empresa, el cual contiene políticas y controles detallados íntegramente de todas las actividades a realizarse en una tarea específica; la construcción de los manuales es función de los directores, gerentes, dueños o accionistas de las instituciones; ya que sirven estratégicamente para la toma de decisiones; además, permiten mantener una eficiente comunicación con el talento humano al interior de la empresa, sobre la forma de realizar las funciones de su competencia y evitar cuellos de botella y entorpecimiento en los procesos; al mismo tiempo, los manuales de procedimientos contables generan un vínculo con el constructor de responsabilidad social 
empresarial, como herramienta de control interno en la rendición de cuenta de cada directivo, funcionario o empleado.

$\mathrm{Al}$ respecto, Palma (2010) manifiesta que el manual de procedimientos es un documento del sistema de control interno, el cual se crea para obtener una información detallada, ordenada, sistemática e integral que contiene todas las instrucciones, responsabilidades e información sobre políticas, funciones, sistemas y procedimientos de las distintas operaciones o actividades que se realizan en una organización; de acuerdo a lo manifestado por el autor, el manual de procedimientos adquiere enorme significancia para el personal que labora dentro de una entidad, ya que se encarga de detallar y enfatizar cada paso de una actividad.

Dessler (2016) manifiesta que los manuales de procedimientos contables son documentos que sirven como medios de comunicación y coordinación que permiten registrar y transmitir de forma ordenada y sistemática, información de una organización, así como las instrucciones y lineamientos que se consideren necesarios para el mejor desempeño de sus tareas.

Según Carrasco (2014), el manual de procedimientos es un documento que contiene, en forma ordenada y sistemática, información y/o instrucciones sobre historia, organización, política y procedimientos de una empresa, que se consideran necesarios para la mejor ejecución del trabajo.

En la misma perspectiva, para el autor Gómez (2011) el manual de procedimientos es un instrumento de apoyo en el que se encuentran de manera sistemática los pasos a seguir, para ejecutar las actividades de un puesto determinado y/o funciones de la unidad administrativa. Un manual de procedimientos es un escrito donde se concentran procesos indispensables para desarrollar una tarea en forma ordena y metódica. De igual manera, Álvarez (2012) afirma que dentro de un manual de procedimientos existen diversos sistemas que pueden ser empleados en función de los múltiples factores, como la periodicidad contable, el control financiero, los procesos de control, entre otros; asimismo, Saiduvis (2011) manifiesta que el manual de procedimientos procesa la información pertinente a nivel financiero de dicha compañía, donde busca acelerar el proceso de viabilidad y esclarecimiento en el departamento contable de dicha entidad.

Dentro de la fundamentación teórica es necesario destacar la cimentación teórica que vincula a los procedimientos contables como parte fundamental del manual, objeto de estudio indicando que son aquellos procedimientos ejecutados en una empresa o institución; su principal objetivo es brindar la ayuda necesaria sobre el manejo ordenado y sistemático de las cuentas que integran cada procedimiento en la contabilidad y el tratamiento que se le dé a las mismas, estos procedimientos ayudan a la persona encargada del área contable a optimizar de una manera rápida y oportuna la información pertinente para la debida toma de 
decisiones por parte de la alta gerencia, encaminadas siempre al bienestar de la institución Chiriboga (2014).

De esta manera, los procesos contables se caracterizan por incluir procedimientos que permiten expresar a través de estados financieros las operaciones económicas de una empresa, entidad u organización (Carvalho, 2016), durante el período contable permite la observación y el análisis de gastos e ingresos con la finalidad de efectuar proyecciones que beneficien en el progreso institucional. Por otra parte, Barreto y Teodomiro (2018) manifiestan que el proceso contable inicia con la identificación de operaciones que pueden ser rutinarias, aquellas operaciones efectuadas en forma constante.

\section{Cimentación teórica del control interno}

La variable que resulta ser importante para el manual de procedimientos contables es el control interno, cuya fundamentación teórica se expone de acuerdo a la posición de diferentes autores; Aguirre (2008) define al control interno como un conjunto de procedimientos, políticas, directrices y planes de organización los cuales tienen por objeto asegurar una eficiencia, seguridad y orden en la gestión financiera, contable y administrativa de la empresa. Es transcendental destacar que esta definición de control interno no solo abarca el entorno financiero y contable sino también los controles cuya meta son la eficiencia administrativa y operativa dentro de una organización empresarial.

En este sentido, Aguilar y Cabrale (2010) señalan que el control interno tiene su origen en la gestión administrativa de las organizaciones, además de encontrarse integrado a los procesos administrativos; estos también pueden ser considerados como un conjunto de normas que se utilizan en la medición del control interno y ayudan a determinar su eficacia y eficiencia. Por su parte, Tesen y Vásquez (2012) exponen que un eficiente sistema de control radica en que su principal propósito es detectar con oportunidad, cualquier desviación significativa en el cumplimiento de las metas y objetivos establecidos, por consiguiente, es necesario que el control interno promueva la eficiencia de las operaciones, ayudando a reducir los riesgos.

En este orden de ideas, un ambiente de control adecuado, permite que las organizaciones tengan la seguridad de llevar a cabo procesos que se encuentren exentos de fallas significativas, evita el uso no autorizado de los recursos y propicia la realización y registro eficiente de las operaciones, en consecuencia, se obtendrán estados financieros razonables que son una real representación de la situación económica y financiera de las organizaciones (Escalante, 2014).En tal razón, se puede afirmar que existe dentro de las organizaciones un adecuado control interno si se evidencian una adecuada estructura organizativa, si se aplican correctamente las políticas administrativas y si el personal cumple con las leyes y políticas propuestas por la empresa. 


\section{Conceptualizaciones de la contabilidad}

Otra concepción de real importancia para la creación de un manual de procedimientos contables es la teoría relacionada con la contabilidad que ha existido desde tiempos remotos y su evolución ha sido progresiva logrando hasta la actualidad y con la ayuda de la tecnología convertirse en una herramienta de vital importancia dentro de las organizaciones, generando información en un tiempo determinado; en definitiva durante su evolución el objetivo principal de la contabilidad ha sido cubrir la necesidad de información contable en ese momento, con el propósito de corregir errores y tomar decisiones de una manera oportuna. En efecto, la ciencia contable es definida como, el instrumento que permite identificar, presentar y estudiar los diferentes procedimientos contables que una entidad desarrolla en un lapso de tiempo establecido, favoreciendo de tal forma al conocimiento de los resultados logrados y a la elaboración los diferentes estados financieros, los mismos que servirán de base para la toma de decisiones gerenciales (Zapata, 2017).

Para mantener un adecuado sistema contable se debe considerar que los principios, normas y políticas contables son un conjunto de reglas generales que sirven de guía para el desarrollo y dirección de las diferentes actividades a ser ejecutadas en el área contable, esto ayuda a emitir criterios sobre la forma de elaboración de los estados financieros, con el objetivo de tener un marco de referencia, el mismo que debe estructurarse bajo los principios de contabilidad generalmente aceptados (PCGA).

Entre los principales principios están:

a) Principio de partida doble: es el método que la contabilidad utiliza al momento de registrar los movimientos contables de la entidad, es decir existe una doble registración unas a saldos deudores y otros a saldos acreedores.

b) Principios de fondo o valuación: contempla que todos los activos disponibles en la entidad deben ser valuados al costo de adquisición.

c) Principio de registro: esté principio indica que los hechos económicos se contabilizan en el momento en el cual se crean derechos y obligaciones, así como también los gasto e ingresos se contabilizaran en el momento que se incurren.

d) Principio de devengado: es la forma de reconocer y registrar en cuentas las diferentes transacciones en un determinado tiempo.

e) Principio de prudencia: este principio hace referencia, a la manera adecuada que se debe elegir entre dos valores de una cuenta del activo; en este caso se elegirá el valor más bajo.

f) Principio de periodo contable: contempla el tiempo en el cual cada una de las operaciones de la entidad deben ser registradas, con la finalidad que al momento de informar se note claramente las transacciones contabilizadas. 
g) Principio de revelación: contempla la forma en la cual se debe elaborar la información financiera, es decir; la manera ordenada de cada una de las cuentas contables las misma que será expuesta a los usuarios

h) Principio de no compensación: contempla la no compensación de cuentas diferentes, es decir, no se puede compensar cuentas del activo con cuentas del pasivo.

i) Principio de hechos posteriores: son aquellos sucesos ocasionados posteriores a la fecha de formulación de los diferentes estados financieros; ya sea favorables o desfavorables con la finalidad de realizar ajusten a las cuentas anuales si el caso lo amerita

\section{Importancia y ventajas de la contabilidad}

Espejo (2012) considera que la contabilidad desde tiempos anteriores se ha convertido en un instrumento primordial para todo tipo de empresa u organización económica ya que permite obtener resultados eficaces y oportunos de sus los movimientos económicos, por tanto, la posibilidad de obtener resultados positivos cuantos negativos depende del manejo y atención que se da a los bienes económicos que poseen las mismas.

La importancia de la contabilidad radica en el propósito de facilitar y proporcionar información financiera a sus usuarios, esta información tiene que ser veraz, real y de calidad, de tal manera que la misma permita a la gerencia tomar decisiones oportunas en el ámbito económico, de tal manera, que la organización mantenga su solvencia y liquidez. La información que la contabilidad brinda permitirá realizar un análisis de todos los movimientos económicos que se han generado en una entidad u organización, de tal manera que transparente el uso adecuado de los fondos económicos con los que cuenta la misma.

\section{Principios, normas y políticas contables para instituciones financieras del sector popular y solidario}

Los principios, normas y políticas contables son un conjunto de reglas generales que sirven de guía para el desarrollo y dirección de las diferentes actividades a ser desarrolladas en el área contable de las instituciones financieras, esto ayudara a emitir criterios sobre la forma de elaboración de los estados financieros y la aplicación de estos lineamientos en los mismos, con el objetivo de tener un marco de referencia sobre el cual se sustenten la información financiera que se obtenga de los diferentes instrumentos financieros proporcionados por parte de la entidad,

Los instrumentos financieros deben estar enmarcados bajo los principios contables que lo rigen, por ello, los principales elementos que van directamente relacionados con la contaduría, son los principios de contabilidad generalmente aceptados (PCGA), es así que, la Superintendencia de Economía Popular y Solidaria (SEPS), organismo encargado del control y vigilancia de las instituciones financieras populares y solidarias del Ecuador, ha 
emitido un catálogo único de cuentas sustentado en los PCGA, para la elaboración de los estados financieros por parte de estas entidades. Esta guía expone el tratamiento de cada una de las cuentas que pueden ser utilizadas por las instituciones financieras dependiendo su segmentación. Cabe destacar la importancia de cada uno de los principios, debido a que estos se encuentran inmersos en los diferentes cuerpos legales tanto contables como tributarios, por ello, las entidades que integran el sistema popular y solidario aplican estos principios en la elaboración de sus estados financieros.

Desde 2012, la SEPS ha desarrollado funciones de asesoría normativa; tarea que busca la eficiencia de las actividades de supervisión y desarrollo del sector. A través de la emisión de normas han procurado impulsar el control interno (administrativo, financiero y contable) de las organizaciones de la economía popular y solidaria; así como, fortalecer la gestión de riesgo; regular los procesos de supervisión, fusión y liquidación, que han aportado en la prevención de lavados de activos y financiamiento de delitos. En este contexto, las normas aprobadas reconocen la heterogeneidad del sector y establecen un tratamiento diferenciado según la segmentación de las entidades. La economía popular y solidaria demanda de considerables estrategias para su crecimiento y consolidación, pero ha sido fundamental el desarrollo normativo, es así que, durante su gestión suman 107 normas de regulación y control emitidas desde 2012; entre ellas, existieron propuestas de regulación que fueron emitidas por la Junta de Política Monetaria y Financiera, y por la SEPS, en el ámbito de sus acciones de control. Bajo el amparo de la normativa vigente la SEPS ha procurado mejorar el gobierno cooperativo, consolidando los procesos de control interno y desarrollando capacidades para la gestión de riesgo.

La información que antecede, pone en evidencia, que en el siglo XXI considerado como el siglo del conocimiento, la comunicación y la informática; la sistematización de la información en las instituciones financieras que están dentro de la economía popular y solidaria, es imprescindible; por lo que, éstas deben incorporar la sistematización de la información en cada uno de sus departamentos ya sea administrativo, financiero, talento humano, contable. En este contexto, la importancia de que la contabilidad sea elaborada de manera sistemática reside en la utilidad que brinda al momento de controlar todas las operaciones contables generadas por la entidad, contribuyendo a que la institución cuente con información clara, confiable y oportuna, para la debida toma decisiones internas como externas que favorezcan al crecimiento y desarrollo institucional; así mismo ayuda a la elaboración y entrega de informes a los diferentes organismos de control a los cuales están sujetos. En efecto, el valor de la sistematización de la información contable en las entidades va estrechamente ligada a conocer y entender todos los procedimientos contables desarrollados y la forma o métodos que se utilizaron para la obtención de estos datos, de esta forma, se puede dar respuesta inmediata a la satisfacción de las necesidades y expectativas de los usuarios que tienen acceso a la información. 
En conclusión, es importante que toda entidad financiera defina y disponga de procedimientos sistematizados en la elaboración de la información contable, expresados en un manual de procedimientos contables automatizados, ya que esto permitirá que se viabilice el direccionamiento económico, contable y financiero de la entidad, además, de admitir información más comprensible a fin de brindar confianza sobre el manejo de los recursos con los que cuenta.

\section{Metodología.}

El artículo asumió un diseño no experimental, en razón que no se incurrió en la manipulación de las variables de la investigación, el enfoque que se utilizó para el desarrollo del presente estudio fue de tipo mixto (cuali - cuantitativo); el enfoque cualitativo se argumentó por la indagación de la bases teóricas que sustentaron la propuesta y el enfoque cuantitativo por cuanto se recolectaron y explicaron datos contables y estadísticos relacionados con la naturaleza propia de la empresa; el alcance del documento investigativo es descriptivo explicativo, transversal y de campo.

Se recurrió el método histórico - lógico ya que se analizó las variables de estudio bajo un orden cronológico y con una secuencia lógica, además se empleó el método deductivoinductivo, el mismo que facilito la identificación de procesos y actividades en la entidad. En lo referente a las técnicas e instrumentos se utilizaron encuestas y entrevistas las mismas que fueron aplicadas de manera estratificada a los socios y personal administrativo y directivo de la Cooperativa de Ahorro y Crédito Atlántida de la ciudad de Cañar; estos instrumentos permitieron obtener información a profundidad sobre los diferentes procedimientos efectuados en la entidad. En virtud de lo mencionado, se consideró como universo de estudio a 22 personas que se encuentran relacionadas directa e indirectamente con la ejecución de cada uno de los procedimientos contables que se efectúan.

\section{Resultados}

De la revisión y análisis obtenidos por observación de la visita in situ a la institución, de las encuestas y entrevistas realizadas a la Junta de representantes, Consejo de Administración y Vigilancia, al Gerente y Contador de la Cooperativa de Ahorro y Crédito Atlántida de la ciudad de Cañar, además de la información contable y administrativa disponible, se establecieron las siguientes deducciones:

$\checkmark$ En la cooperativa únicamente se elabora el estado de situación financiera y el estado de resultados; por lo tanto, no existe la producción del estado de flujo de efectivo y el estado de cambios en el patrimonio.

$\checkmark$ Se evidenció que no disponen de procedimientos documentados que permitan registrar de manera correcta cada uno de los movimientos de las cuentas contables; es decir la Cooperativa carece de un manual de procedimientos contables que le conduzcan a una adecuada toma de decisiones, asimismo, en la entidad existen políticas contables, las mismas que no se aplican al momento de realizar las operaciones en la entidad. 
$\checkmark \quad$ Los estados financieros no cuentan con sus respectivas notas explicativas, esto ocasiona un desconocimiento de los cambios significativos que se dan en la situación financiera de la cooperativa.

$\checkmark$ En la cooperativa se elabora el presupuesto en base a los gastos que suponen van a incurrir en un determinado ejercicio económico y los posibles ingresos que cubran esos gastos; esta manera de estructurar los presupuestos no permite que la cooperativa tenga una visión de futuro anclada en datos contables y financieros acordes a la realidad existente.

$\checkmark$ No se aplica ratios financieras que admita conocer el nivel de rendimientos de as cooperativa, pese a que el organismo regulador emite resoluciones de la aplicación de estos métodos.

Los resultados antes expuestos muestran una derivación importante en la elaboración de la información contable, misma que incide de manera significativa en el desempeño de las actividades en la cooperativa; en virtud de aquello, se considera al manual de procedimientos contables como una herramienta elemental, básica y estratégica para que la entidad, la misma que servirá de base para que la empresa cuente con información clara, veraz, oportuna, honesta e íntegra.

Seguidamente se presentan en la figura 1, los procedimientos contables, para el tratamiento de las cuentas de que integran el grupo de activos de la Cooperativa de Ahorro y Crédito Atlántida.

Figura 1. Esquema de la propuesta de manual de procedimientos contables

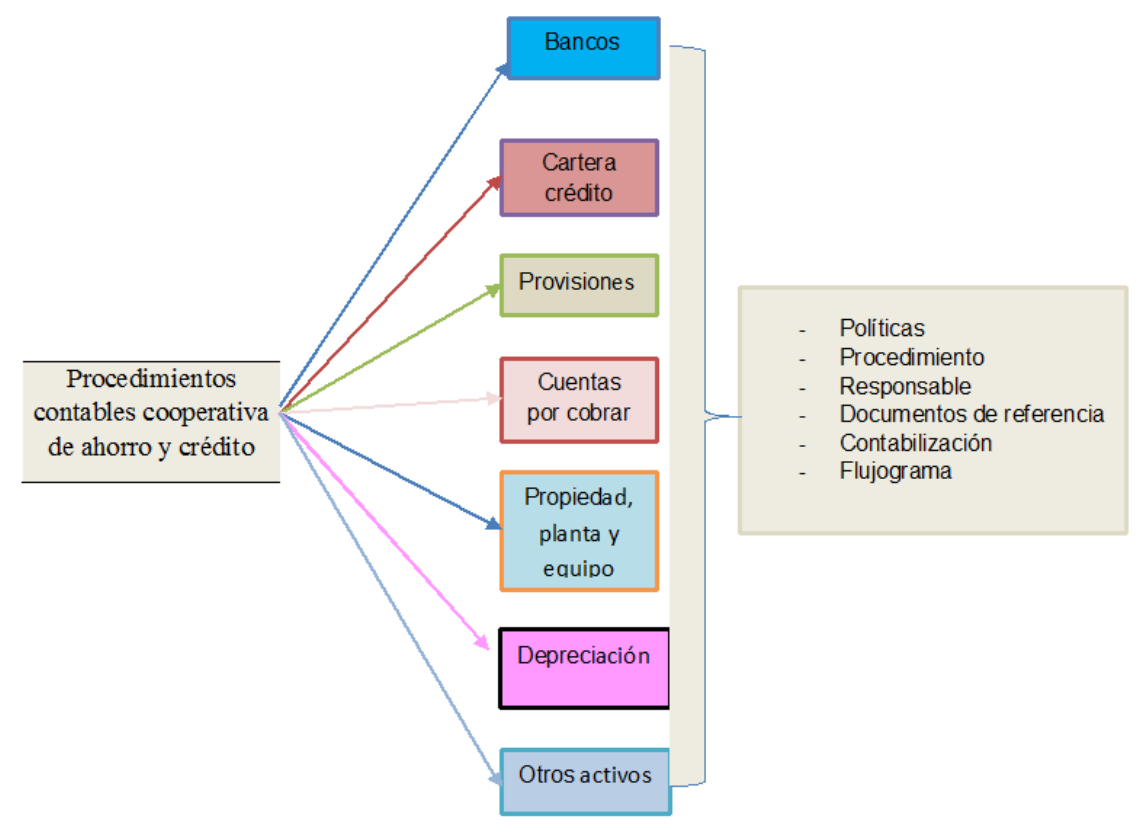


A continuación, se establecen los diferentes elementos con sus respectivos flujogramas que indican la estructura de la propuesta planteada.

Tabla 1. Creación cuenta contable

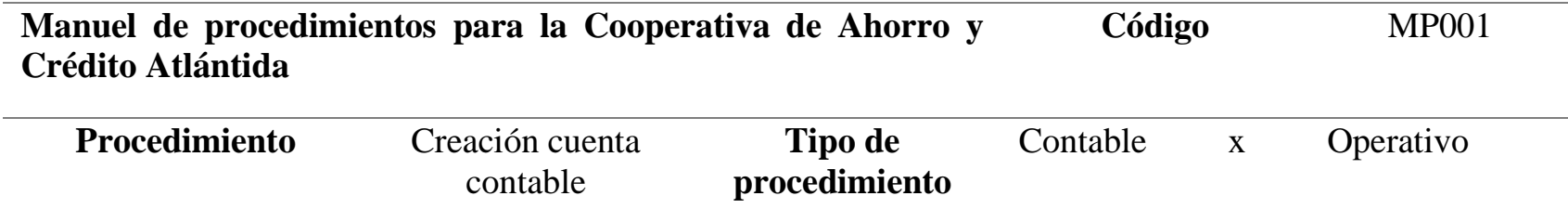

Objetivo: Facilitar al departamento contable las pautas necesarias en la creación de las cuentas contables según las necesidades de la entidad.

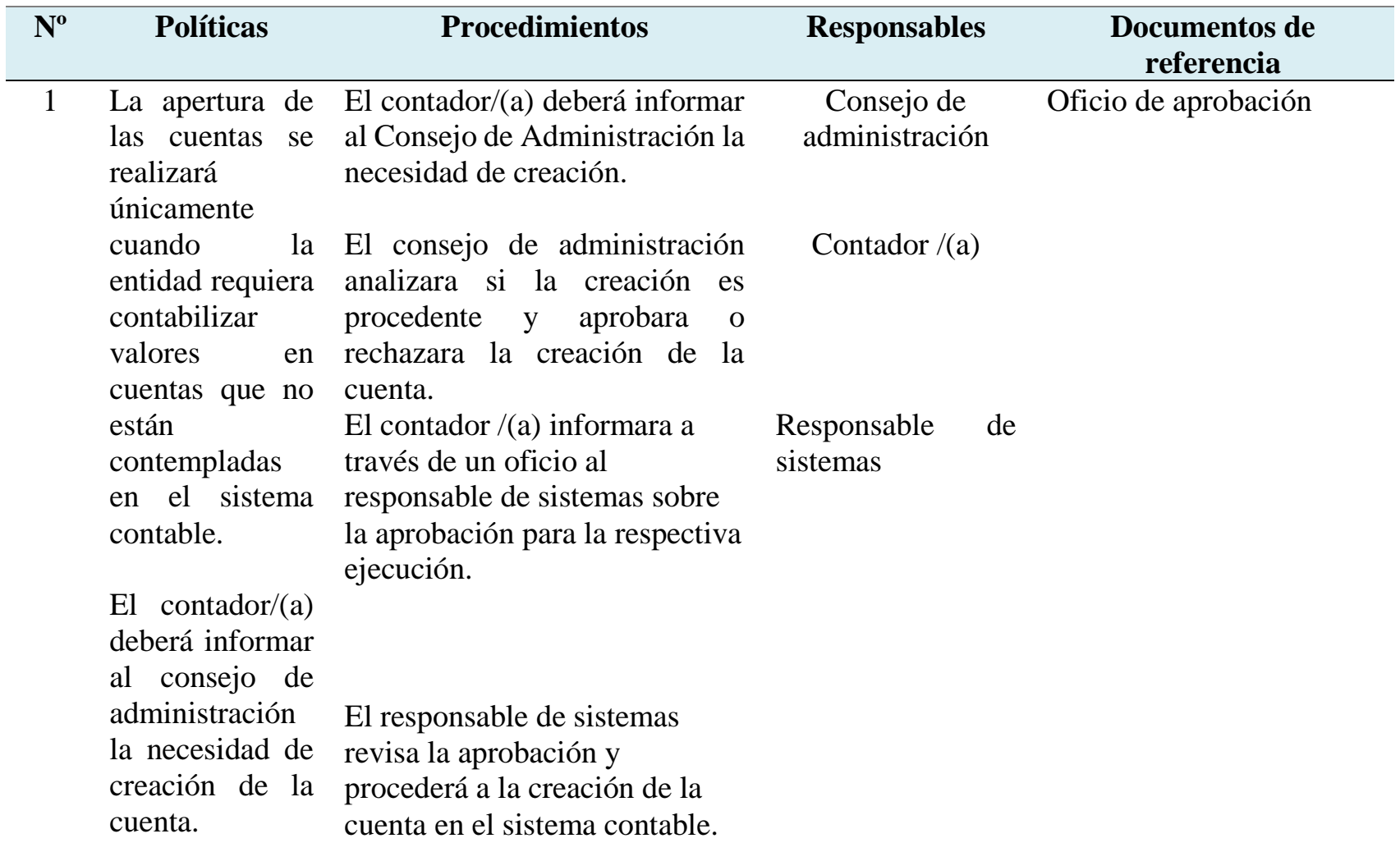


Figura 2: Procedimiento de creación cuenta contable.

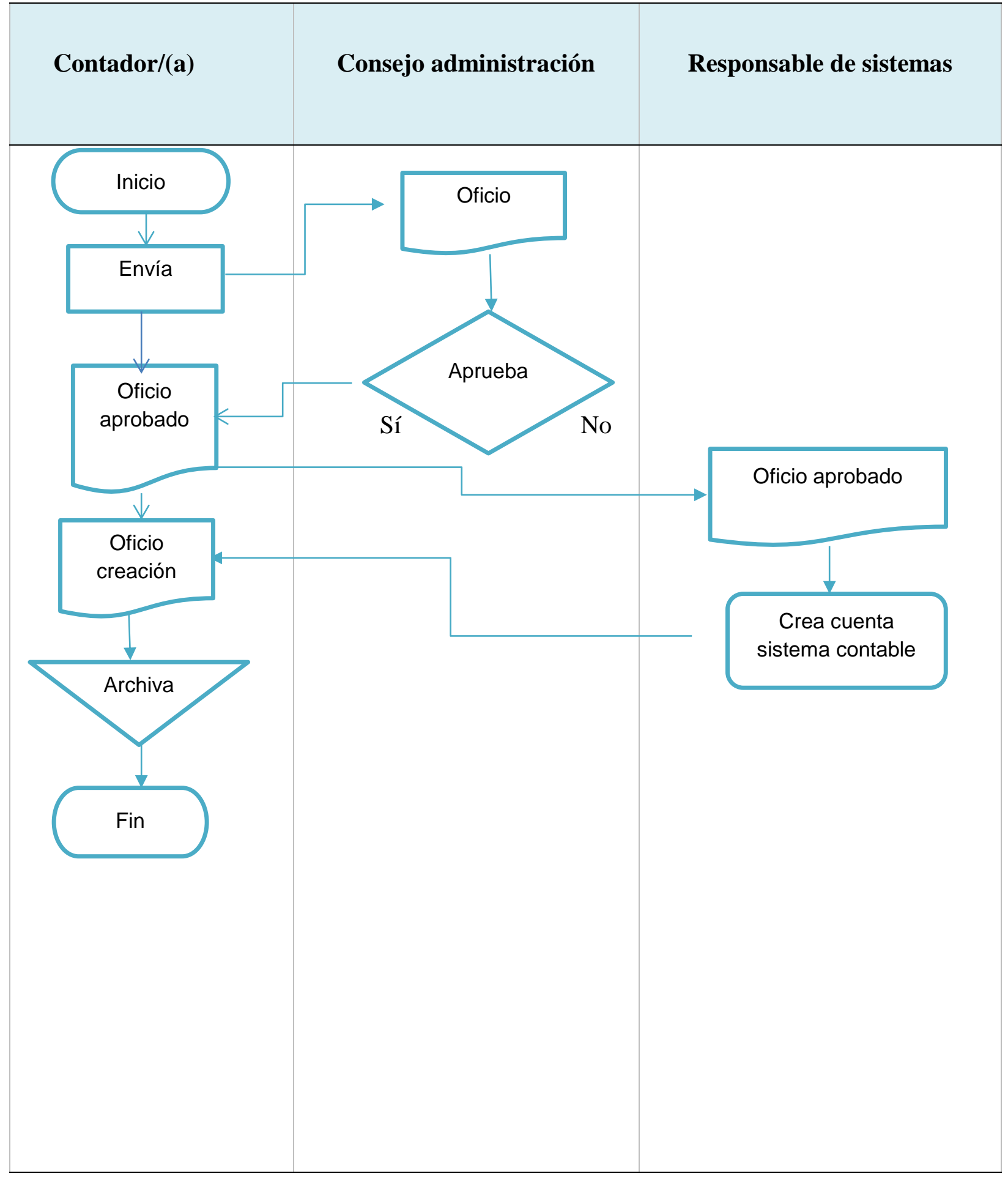


ISSN: 2602-8506

Tabla 2. Reversión cuenta contable

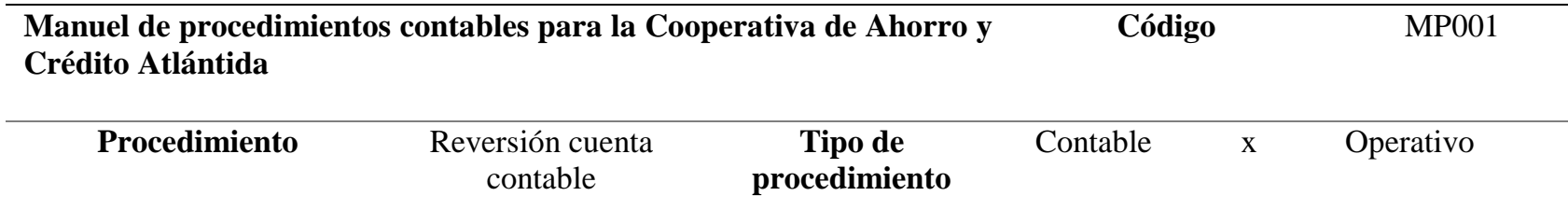

Objetivo: Proporcionar al área contable los pasos para la aplicación de reversión de cuentas contables requeridas por la entidad.

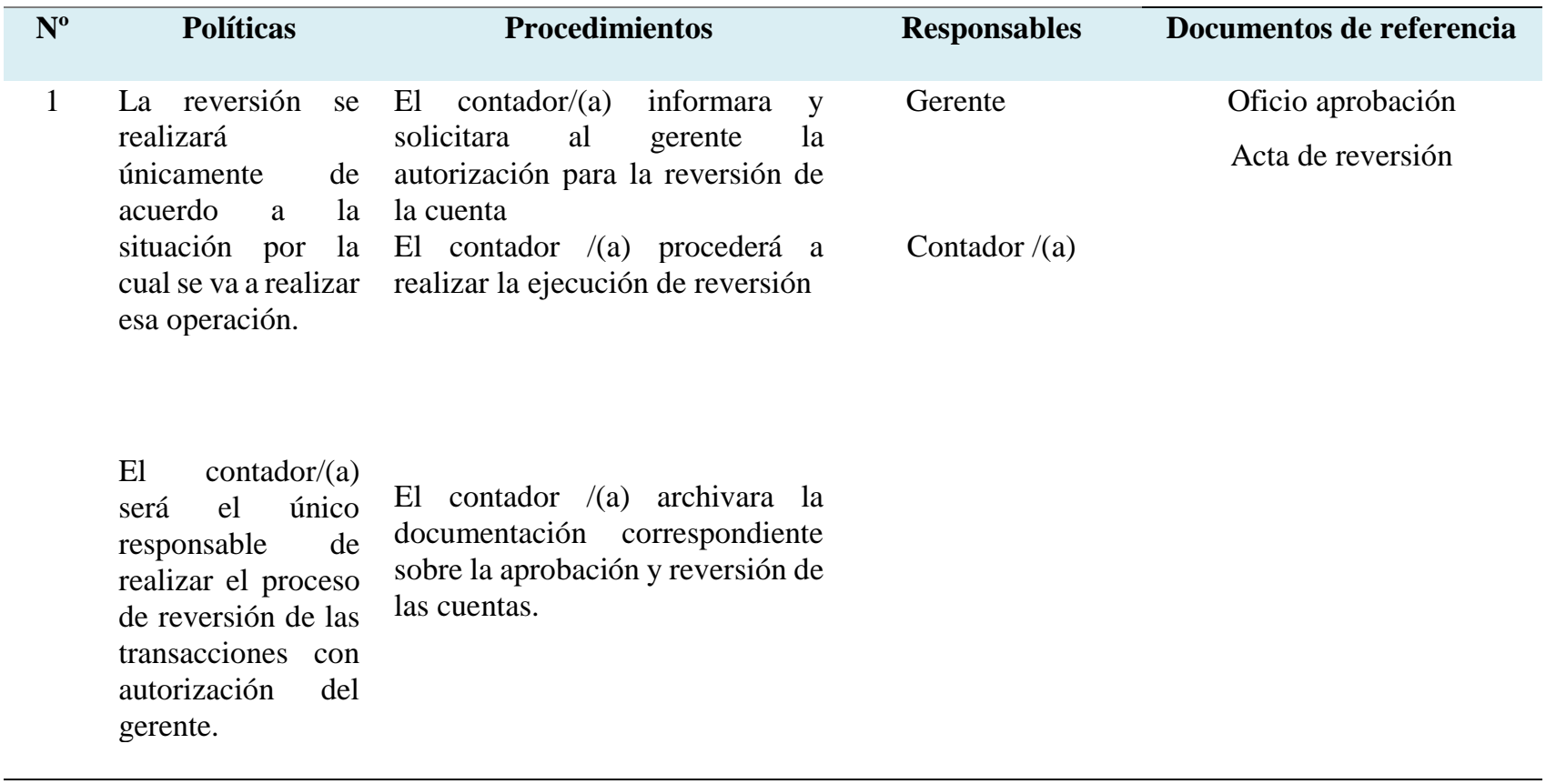

Tabla 3. Contabilización reversión

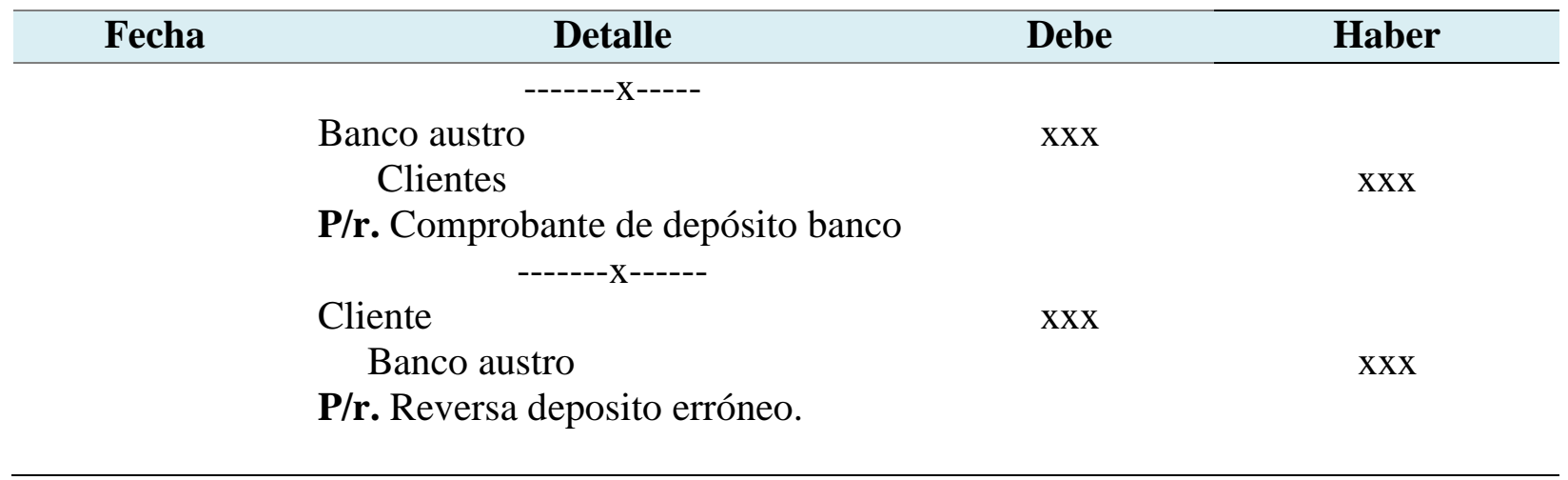




\section{Dinámica}

$\checkmark$ Se debita por saldos a favor

$\checkmark$ Se acredita por saldos en contra

Figura 3: Procedimiento reversión cuenta contable.

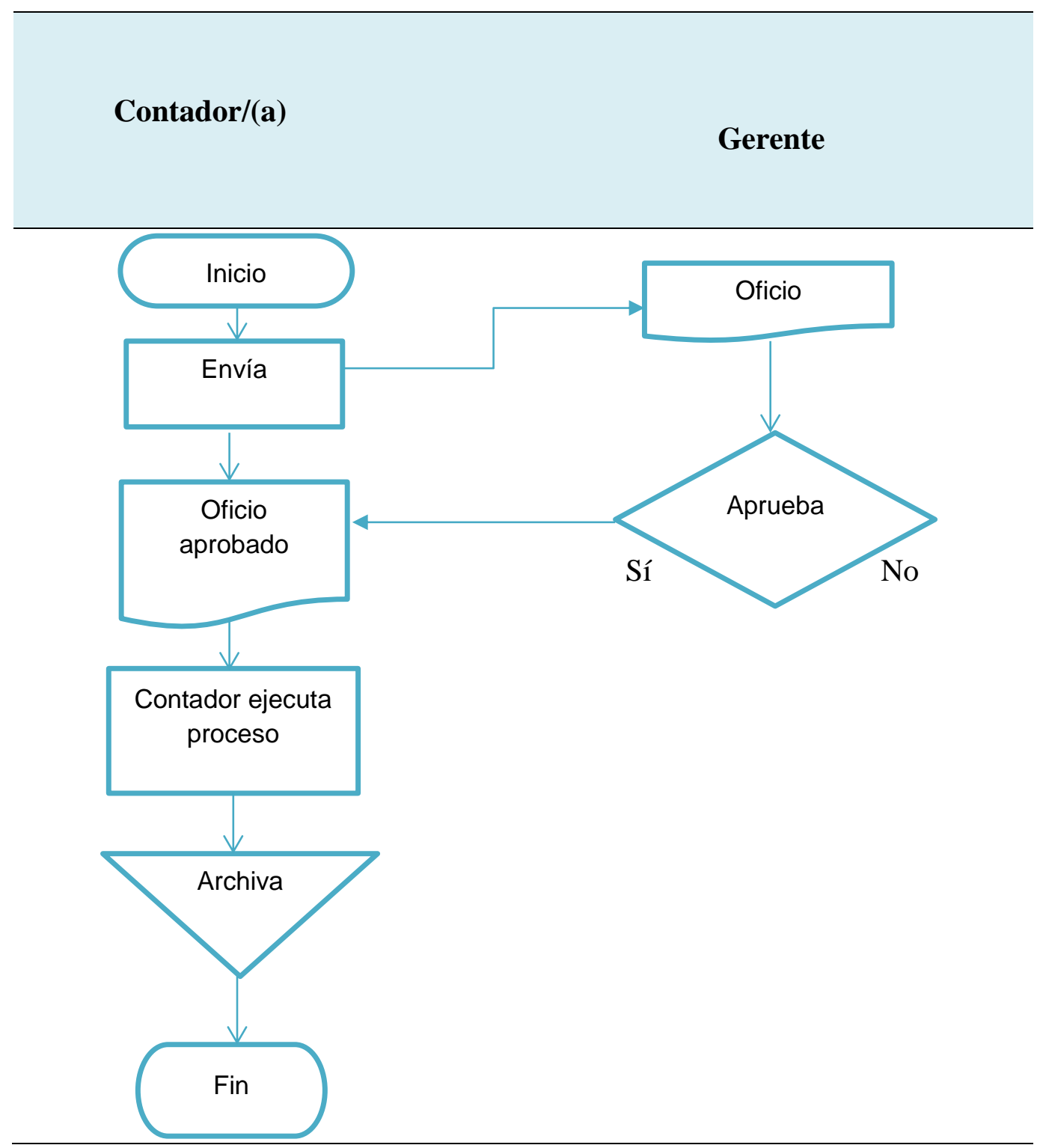


ISSN: 2602-8506

Tabla 4. Manejo cuenta caja

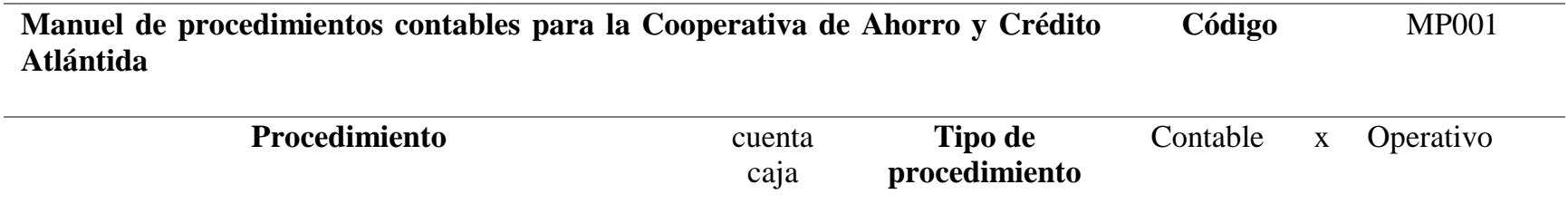

Objetivo: Indicar a los colaboradores el manejo y tratamiento de caja general

\begin{tabular}{|c|c|c|c|c|}
\hline $\mathrm{N}^{\circ}$ & Políticas & Procedimientos & Responsables & $\begin{array}{c}\text { Documentos de } \\
\text { referencia }\end{array}$ \\
\hline 1 & $\begin{array}{l}\text { El responsable de caja será el encargado de } \\
\text { realizar la apertura de caja }\end{array}$ & $\begin{array}{l}\text { El encargado de caja } \\
\text { realiza la apertura del } \\
\text { día verificando los }\end{array}$ & Gerente & Cierres diarios \\
\hline & $\begin{array}{l}\text { Se deben verificar los billetes de } \$ 100 \text { y } \$ 50 \text { y } \\
\text { registrar a través de un formulario de } \\
\text { recepción, en caso de existir falsos serán }\end{array}$ & saldos del día anterior & & $\begin{array}{l}\text { Reportes de saldos } \\
\text { caja }\end{array}$ \\
\hline & En caso de existir faltantes se procederá a & $\begin{array}{lr}\text { El gerente verificara y } \\
\text { aprobara } & \text { el } \\
\text { documento } & \text { de } \\
\text { apertura } & \end{array}$ & & \\
\hline
\end{tabular}
descontar del sueldo del responsable y en caso de existir sobrante de dinero se sumará a caja el valor sobrante.

Las entradas y salidas de dinero deberán ser respaldadas con sus respectos comprobantes y firmados por el dueño de la cuenta.

Los desembolsos efectuados a través de caja deberán ser previamente consultados y autorizados por la gerente general, y respaldados con un documento formal.

El gerente realizara arqueos de caja sorpresivos en presencia del responsable de caja
El responsable de caja efectuara durante el día sus operaciones

Al finalizar el día el gerente solicitara al responsable de caja el documento cierre respectivo

El gerente $y$ responsable de caja contaran el efectivo y firmaran conjuntamente el documento de cierre.
Responsable de caja 
Tabla 5. Contabilización cuenta caja

\begin{tabular}{|c|c|c|c|}
\hline Fecha & Detalle & Debe & Haber \\
\hline \multicolumn{4}{|c|}{-------X----- } \\
\hline \multicolumn{2}{|r|}{ Caja } & $\mathrm{xxx}$ & \\
\hline \multicolumn{2}{|r|}{ Cuenta ahorro $\mathrm{N}^{\circ} 101$} & & XXX \\
\hline \multicolumn{4}{|c|}{$\mathbf{P} / \mathbf{r}$. deposito efectivo } \\
\hline \multicolumn{4}{|c|}{-------X------ } \\
\hline \multirow{2}{*}{\multicolumn{2}{|c|}{$\begin{array}{l}\text { Cuenta ahorro N. }{ }^{\circ} 201 \\
\text { Caia }\end{array}$}} & $\mathrm{xxx}$ & \\
\hline & Caja & & $\mathrm{XxX}$ \\
\hline & $\mathbf{P} / \mathbf{r}$. retiro cuenta ahorro. & & \\
\hline
\end{tabular}

\section{Dinámica}

$\checkmark$ Se debita por los ingresos de dinero en efectivo tanto en moneda de su local u otras monedas.

$\checkmark$ Se acredita por los egresos de dinero en efectivo tanto en moneda de su local u otras monedas.

Figura 4. Procedimiento cuenta caja.

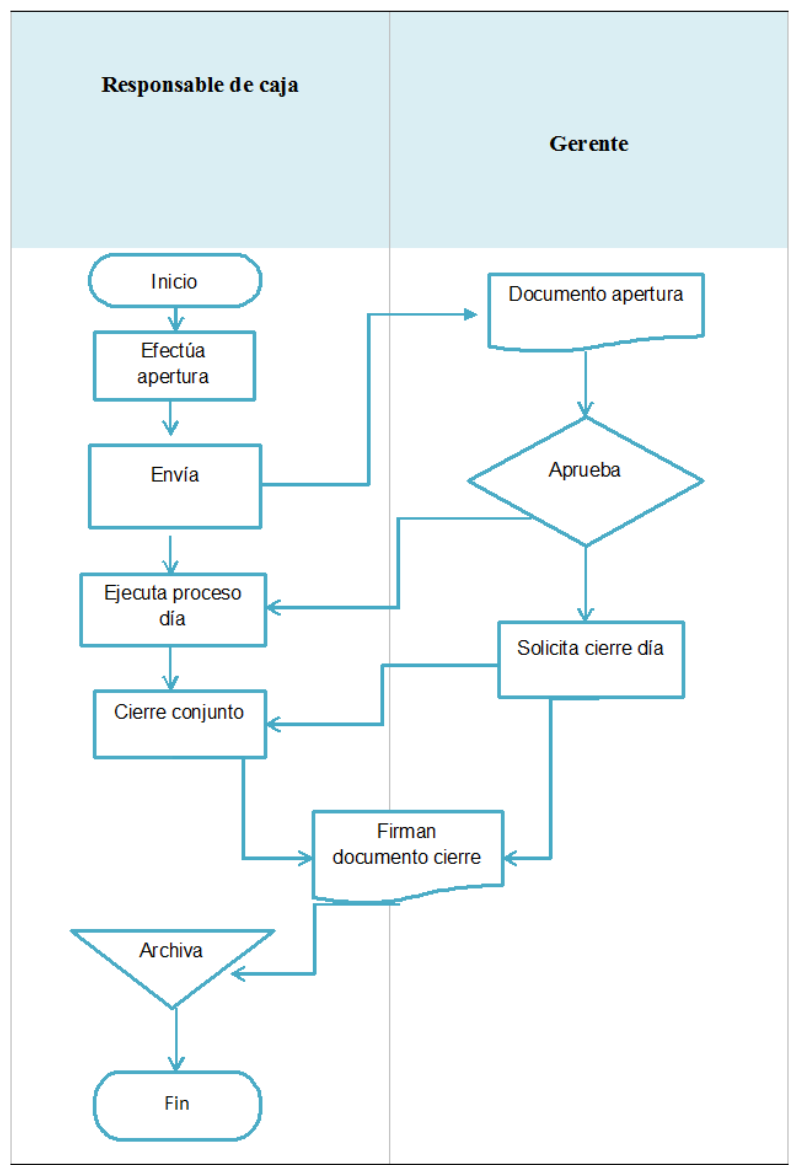


ISSN: 2602-8506

Tabla 6. Creación cuenta caja chica

\section{Manuel de procedimientos contables herramienta de control interno para la Código $\quad$ MP001 Cooperativa de Ahorro y Crédito Atlántida}

$\begin{array}{llcccc}\text { Procedimiento } & \begin{array}{l}\text { Creación } \\ \text { caja chica }\end{array} & \begin{array}{c}\text { Tipo de } \\ \text { procedimiento }\end{array} & \text { Contable } & \begin{array}{c}\text { Operati } \\ \text { vo }\end{array}\end{array}$

Objetivo: Facilitar al custodio de caja chica las pautas para el manejo de fondo de caja chica.

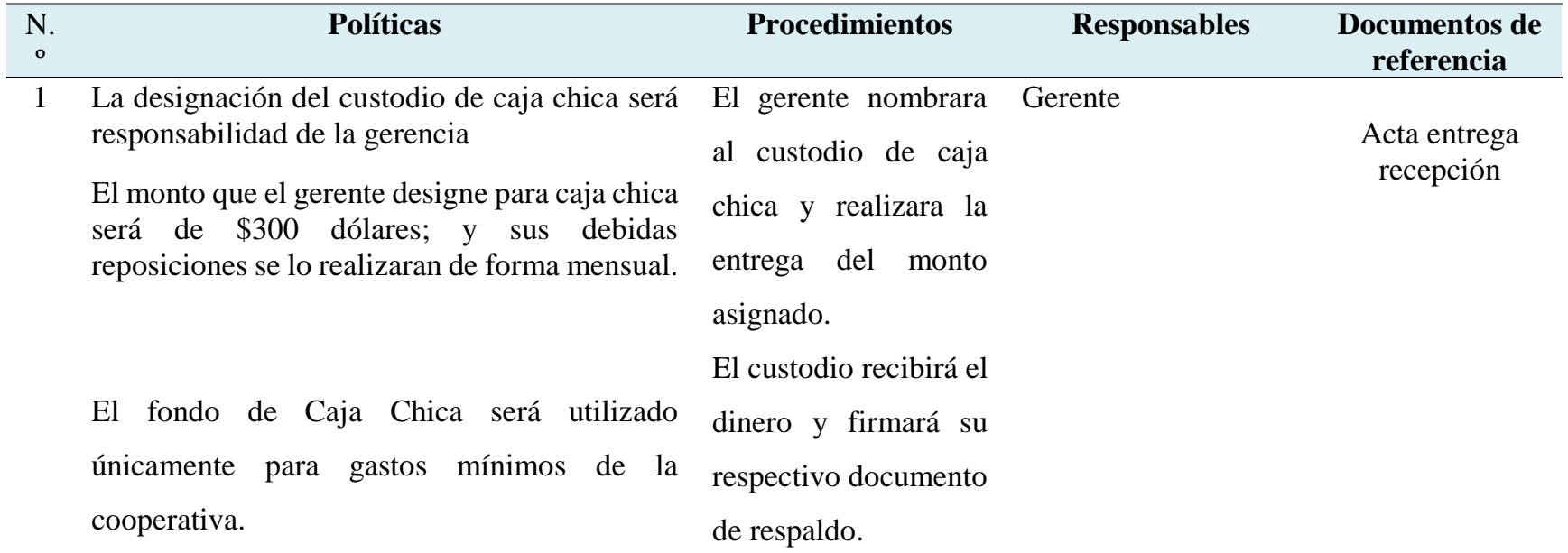

Todos aquellos pagos que se realicen con el fondo de caja chica deberán ser respaldados

El contador (a) con sus respectivos comprobantes. registra en el sistema contable el monto de caja chica.

El gerente archivar el documento de entrega recepción del fondo de caja chica. 
Tabla 7. Contabilización cuenta caja chica

\section{Fecha}

Detalle

Debe

Haber

Caja chica

XXX

\section{Bancos}

-------X------

$\mathbf{P} / \mathbf{r}$. creación monto caja chica

XXX

\section{Dinámica}

Figura 5. Procedimiento cuenta caja chica (creación cuenta)

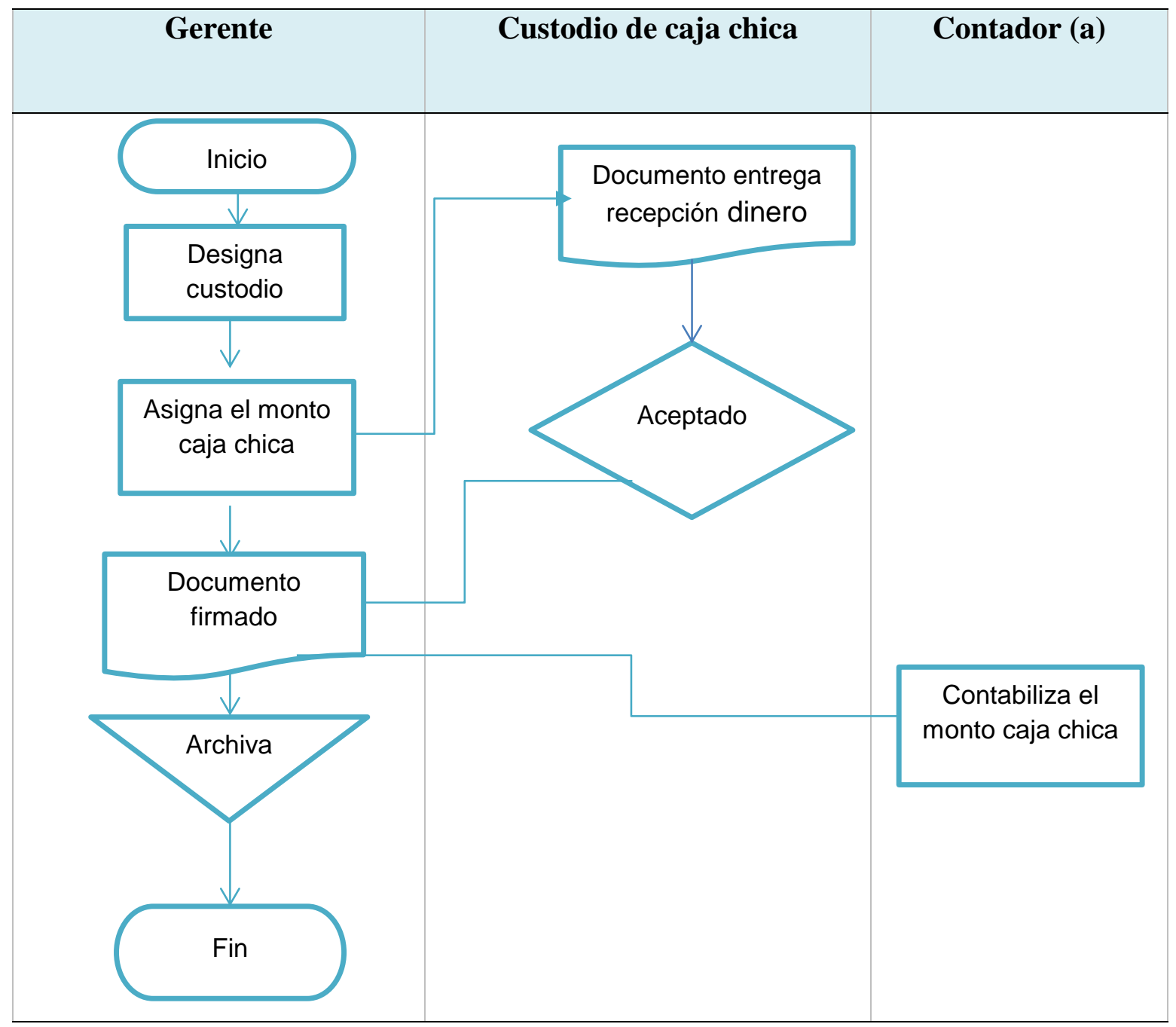


ISSN: 2602-8506

Tabla 8. Manejo cuenta bancos

\begin{tabular}{|c|c|c|c|c|c|}
\hline $\begin{array}{l}\text { Manuel de procedimientos cont } \\
\text { Atlántida }\end{array}$ & perativa & horro y Crédito & Código & & MP00 \\
\hline Procedimiento & $\begin{array}{l}\text { Manejo } \\
\text { cuenta } \\
\text { bancos }\end{array}$ & $\begin{array}{l}\text { Tipo de } \\
\text { procedimiento }\end{array}$ & Contable & $\mathrm{x}$ & $\begin{array}{l}\text { Operativ } \\
\quad \mathrm{o}\end{array}$ \\
\hline
\end{tabular}

Objetivo: Dotar al departamento contable y administrativo los pasos para el debido manejo de las conciliaciones bancarias de la entidad.

N.

1 La conciliación bancaria se realizará de forma mensual.

La conciliación bancaria la realizara la persona responsable del manejo de la cuenta

La conciliación bancaria la realizara la persona responsable del manejo de la cuenta

Las conciliaciones bancarias deberán ser presentadas a la Gerencia de la cooperativa informando las novedades.

e archivarán las conciliaciones bancarias con sus respectivos estados de cuenta.

Procedimientos
El gerente solicitara al
contador (a) un reporte de
los $\quad$ movimientos
bancarios realizado por la
cooperativa.
El contador(a)
solicita al
bancor los estados
bancarios y los recepta.

El contador(a) realiza la verificación de los saldos de los estados bancarios con los registrados en libros contables

El contador(a) entrega al

gerente el informe de la conciliación con sus respectivas observaciones El gerente recibe, revisa la conciliación bancaria la firma y la entrega al contador

El contador(a) recibe la conciliación contabiliza si existen diferencias y archiva documentos.

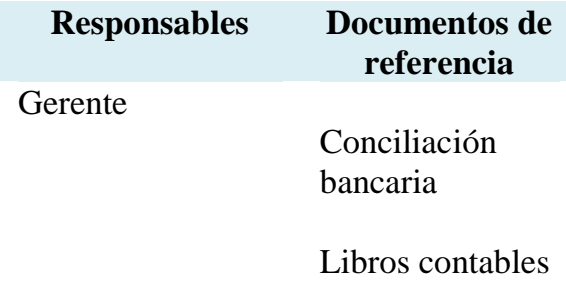

Contador (a) 
Tabla 9. Contabilización cuenta bancos

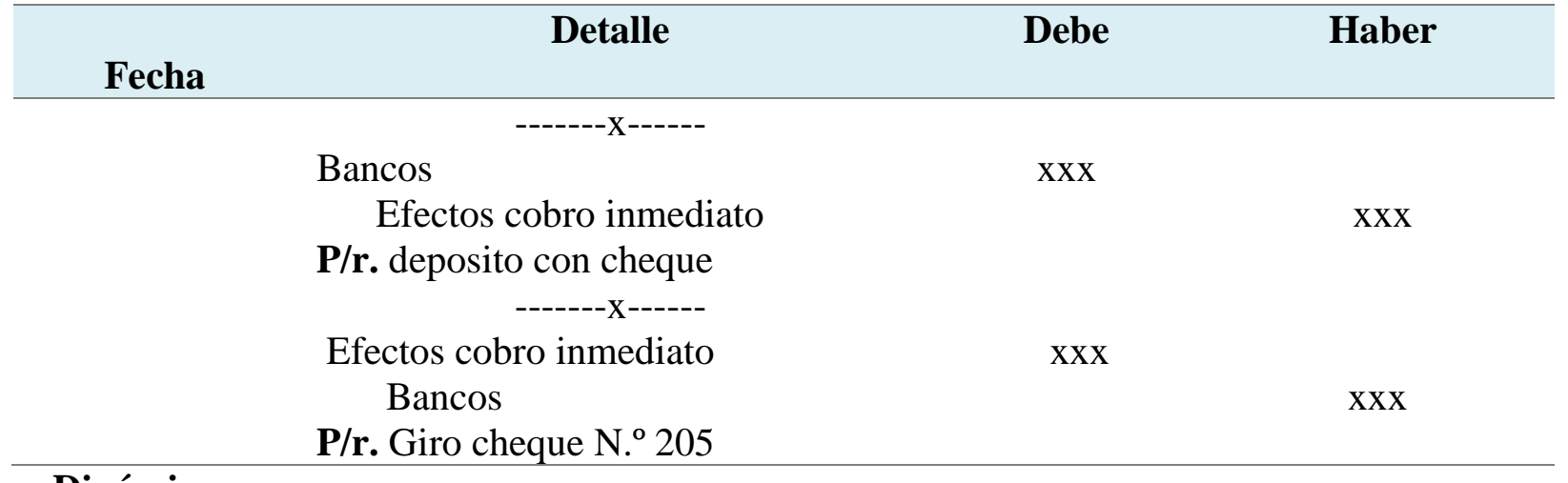

\section{Dinámica}

$\checkmark$ Se debita por los depósitos que se realiza en la cuenta

$\checkmark$ Se acredita por los cheques girados de la cuenta

Figura 6. Procedimiento conciliaciones bancarias.

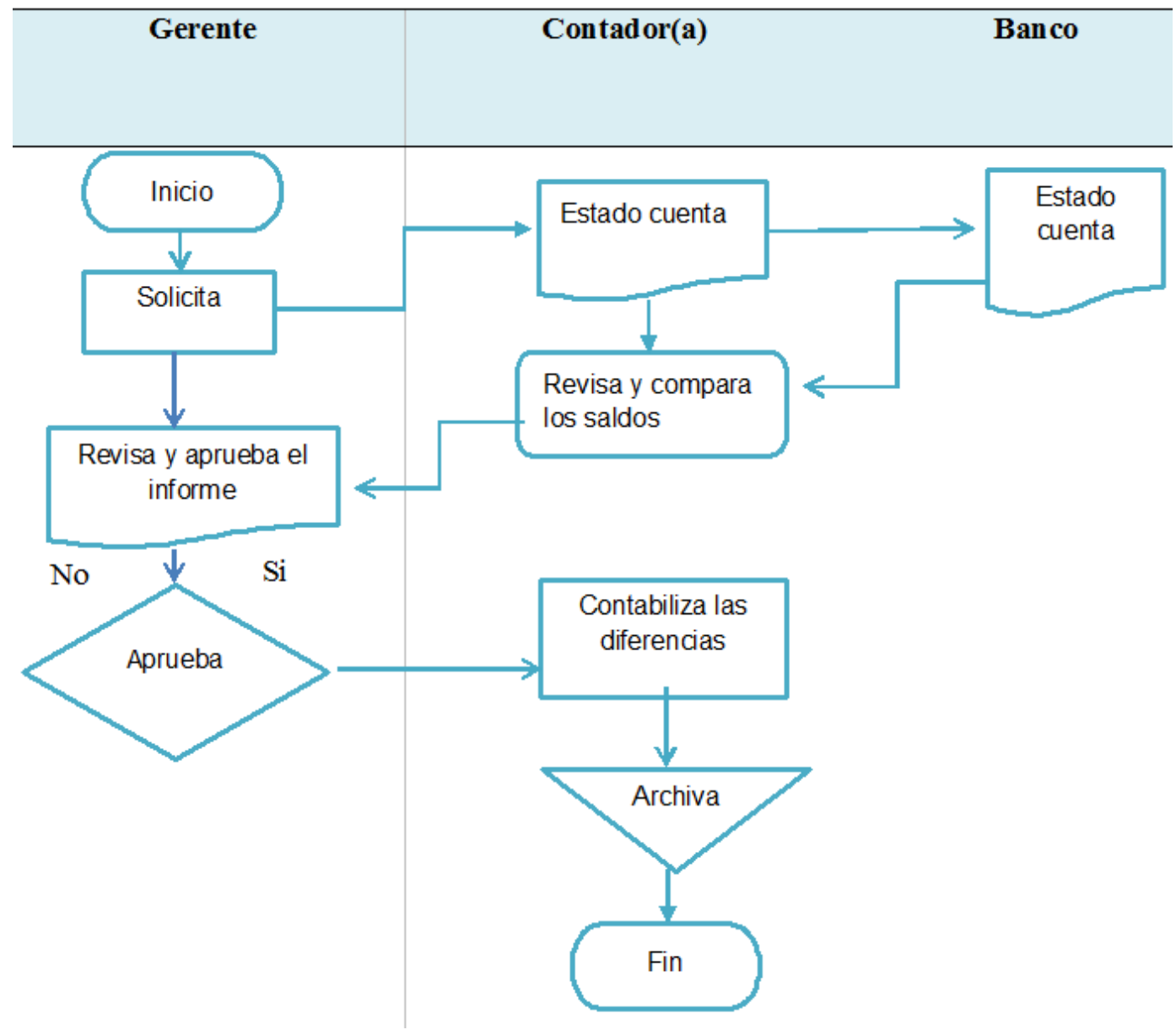


Tabla 10. Concesión crédito

\section{Manuel de procedimientos contables para la Cooperativa de Ahorro y Código MP001 Crédito Atlántida}

\begin{tabular}{|c|c|c|c|}
\hline Procedimiento & $\begin{array}{l}\text { Concesión } \\
\text { de crédito }\end{array}$ & $\begin{array}{c}\text { Tipo de } \\
\text { procedimient }\end{array}$ & Contable \\
\hline
\end{tabular}

Objetivo: Proporcionar al departamento de crédito los pasos para la debida concesión de un crédito en la cooperativa.

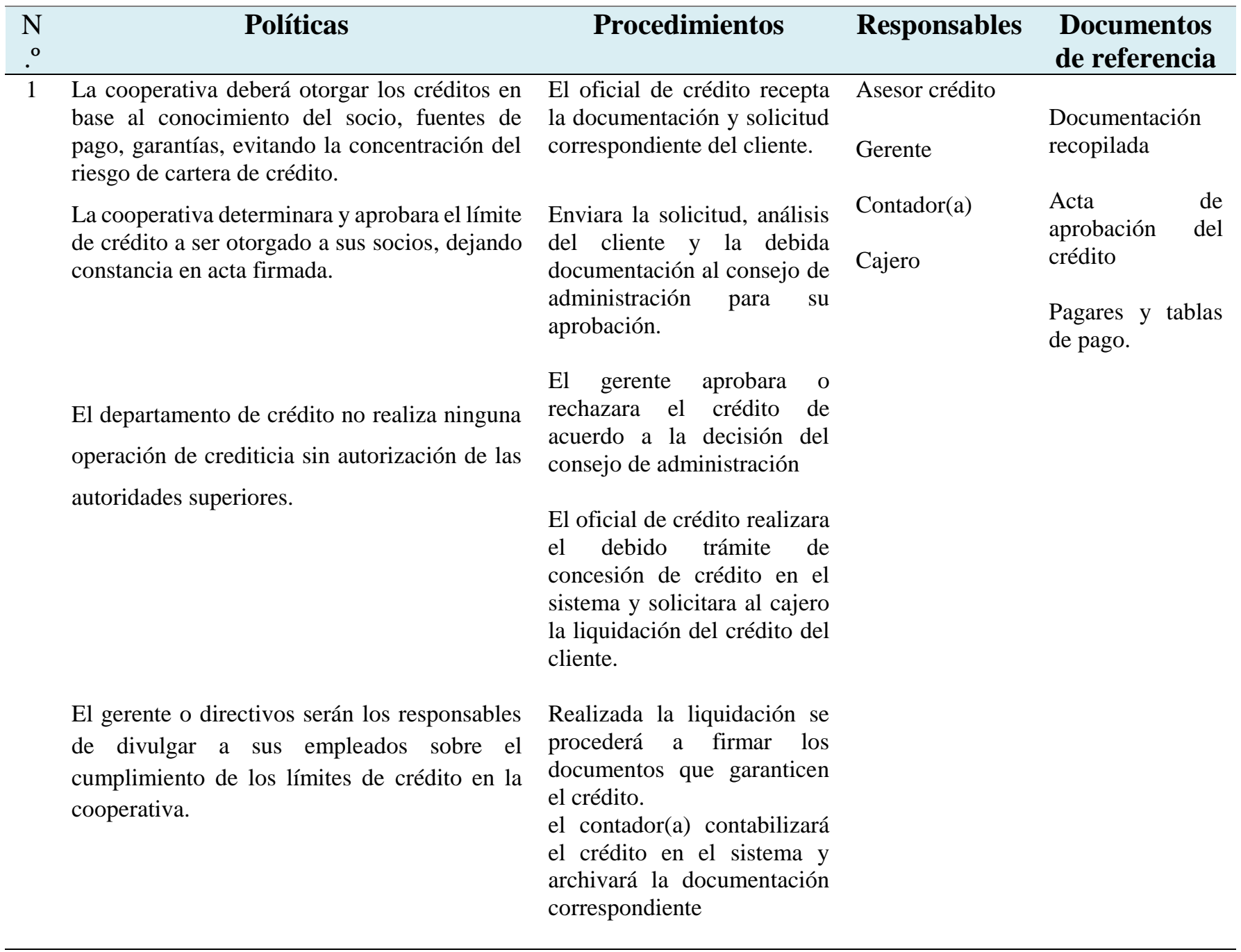


Tabla 11. Contabilización crédito

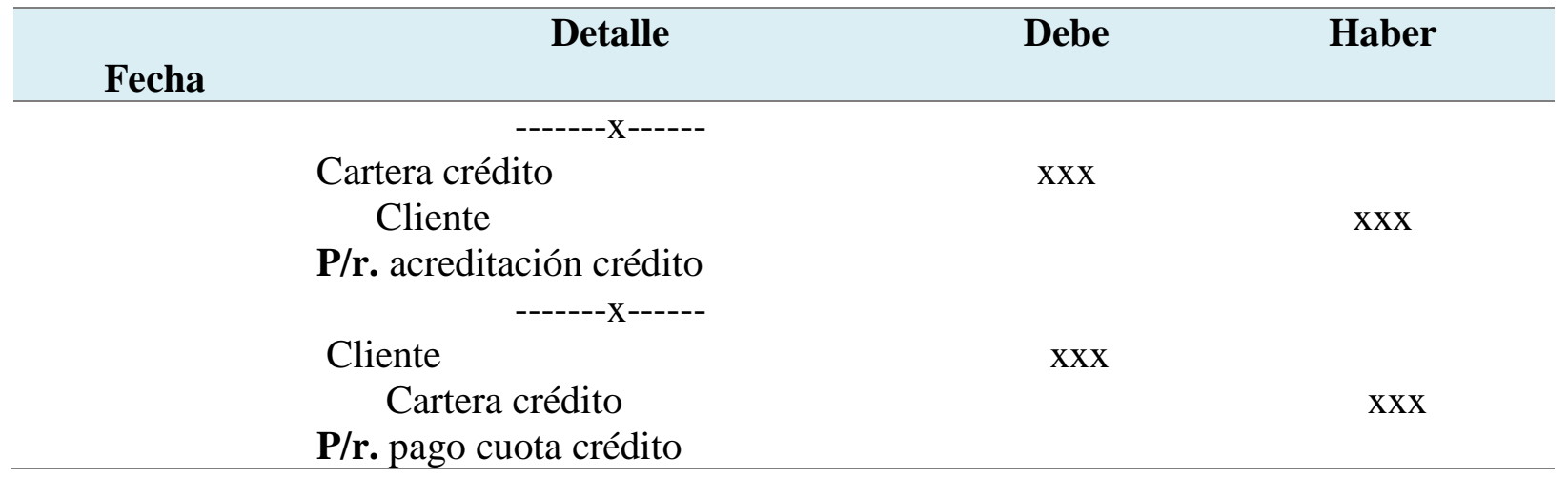

\section{Dinámica}

$\checkmark$ Se debita por el valor del crédito concedido.

$\checkmark$ Se acredita por el abono de las cuotas del crédito concedido.

Figura 7. Procedimiento concesión de crédito.

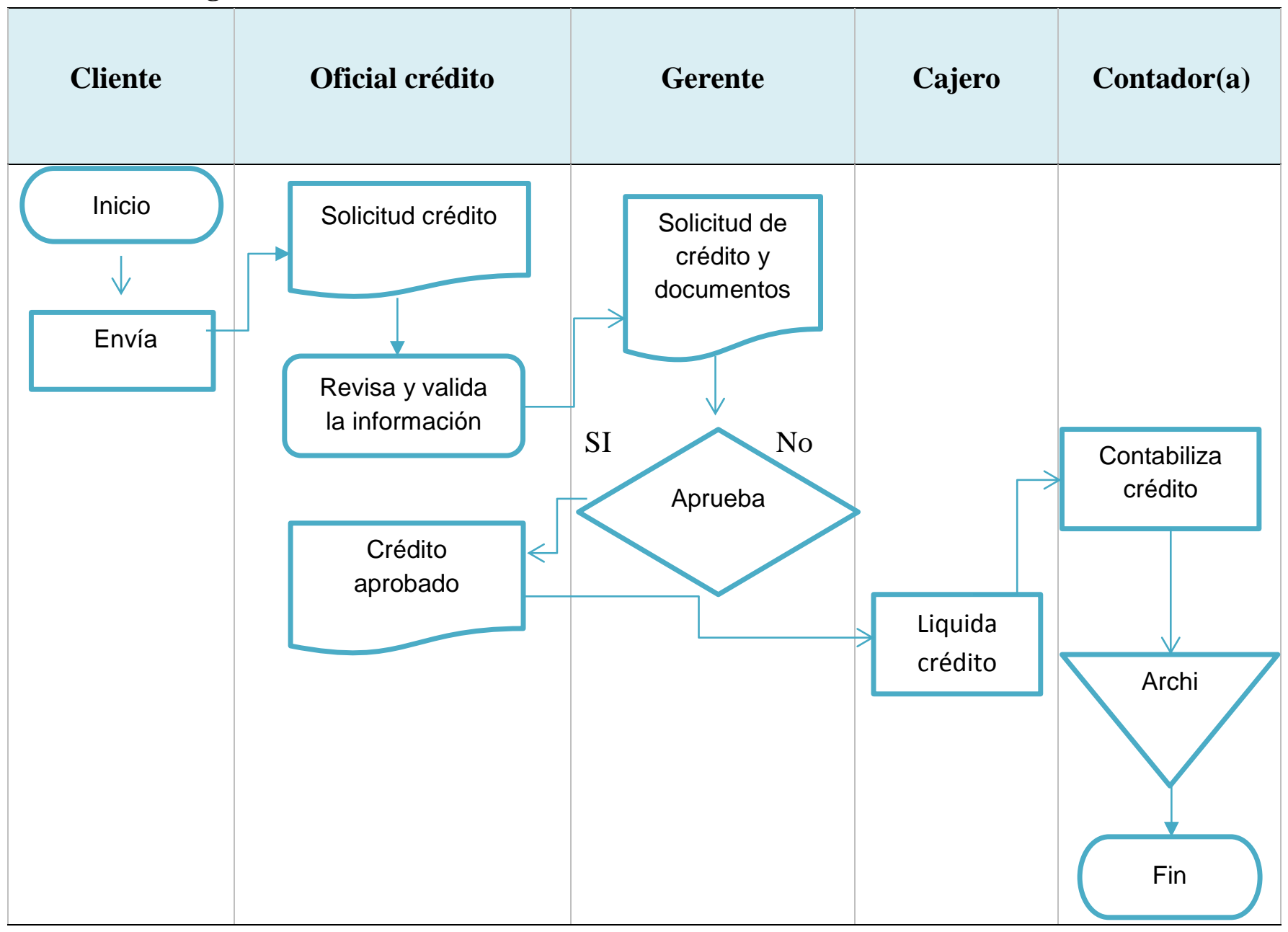


Tabla 12. Provisión cartera crédito

\section{Manuel de procedimientos contables para la Cooperativa de Ahorro y Código $\quad$ MP001 Crédito Atlántida}

$\begin{array}{cccccc}\text { Procedimiento } & \begin{array}{l}\text { Provisión } \\ \text { cartera de } \\ \text { crédito }\end{array} & \begin{array}{c}\text { Tipo de } \\ \text { procedimiento }\end{array} & \text { Contable } & \text { x } & \text { Operati } \\ \text { vo }\end{array}$

Objetivo: Proporcionar al departamento contable las pautas de constitución de la provisión de cartera de crédito.

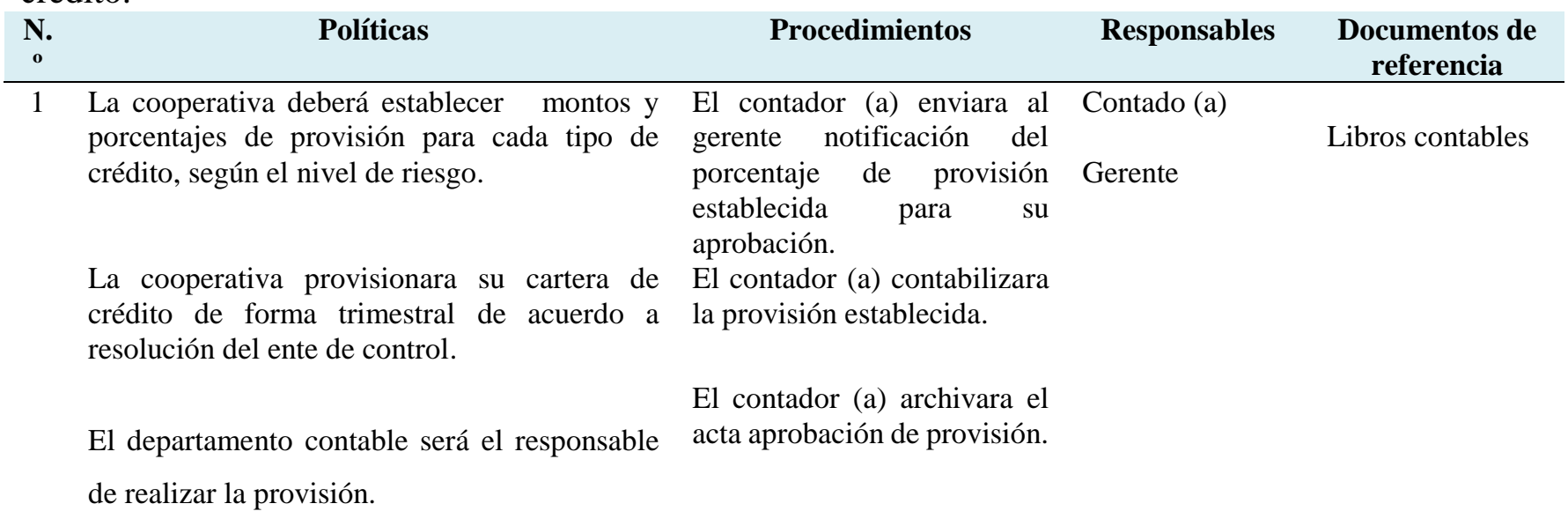

Tabla 13. Contabilización provisión cartera crédito

\begin{tabular}{|c|c|c|c|}
\hline Fecha & Detalle & Debe & Haber \\
\hline & $\begin{array}{l}\text { Provisión cartera crédito } \\
\text { Cartera crédito }\end{array}$ & $\mathrm{xxx}$ & XXX \\
\hline
\end{tabular}


Figura 8. Procedimiento provisión de crédito.

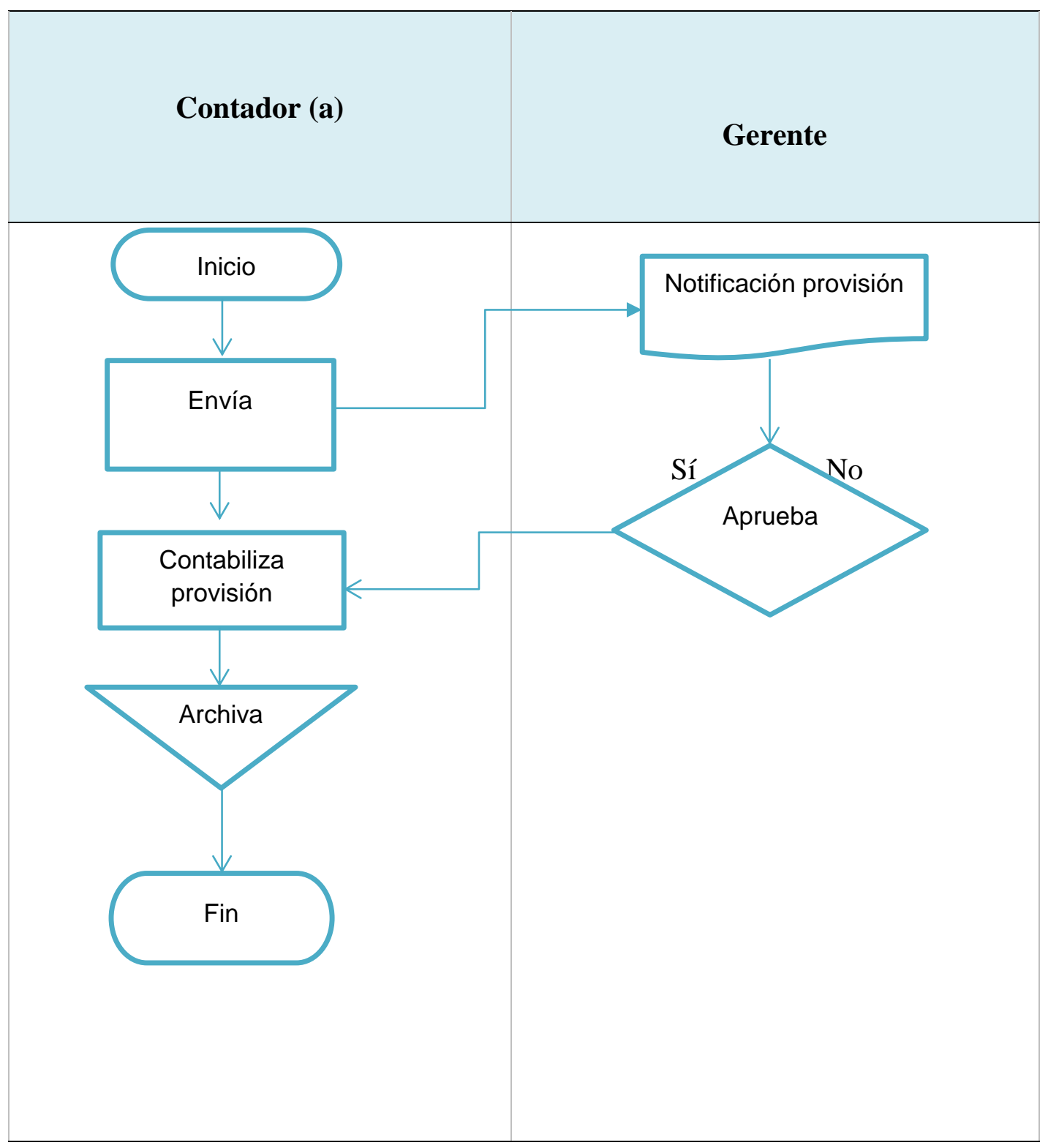


Tabla 14. Cuentas por cobrar

\section{Manuel de procedimientos contables para la Cooperativa de Ahorro y Código MP001 Crédito Atlántida}

$\begin{array}{clcccc}\text { Procedimiento } & \begin{array}{l}\text { Cuentas } \\ \text { por cobrar }\end{array} & \begin{array}{c}\text { Tipo de } \\ \text { procedimiento }\end{array} & \text { Contable } & \text { x } & \begin{array}{c}\text { Operati } \\ \text { vo }\end{array}\end{array}$

Objetivo: Proporcionar al departamento contable el manejo de cuentas por cobrar de la cooperativa.

\begin{tabular}{|c|c|c|c|c|}
\hline $\begin{array}{l}\mathbf{N} \\
.\end{array}$ & Políticas & Procedimientos & Responsables & $\begin{array}{l}\text { Documentos } \\
\text { de referencia }\end{array}$ \\
\hline 1 & $\begin{array}{l}\text { Las cuentas por cobrar de la } \\
\text { cooperativa deberán estar clasificadas } \\
\text { de acuerdo a su naturaleza. }\end{array}$ & $\begin{array}{l}\text { El contador (a) realizara } \\
\text { la clasificación de las } \\
\text { cuentas por cobrar de } \\
\text { acuerdo a su naturaleza } \\
\text { El contador (a) } \\
\text { contabilizara las cuentas } \\
\text { por cobrar de la } \\
\text { cooperativa. }\end{array}$ & Contador (a) & $\begin{array}{l}\text { Libros } \\
\text { contables }\end{array}$ \\
\hline
\end{tabular}

Tabla 15. Contabilización cuentas por cobrar

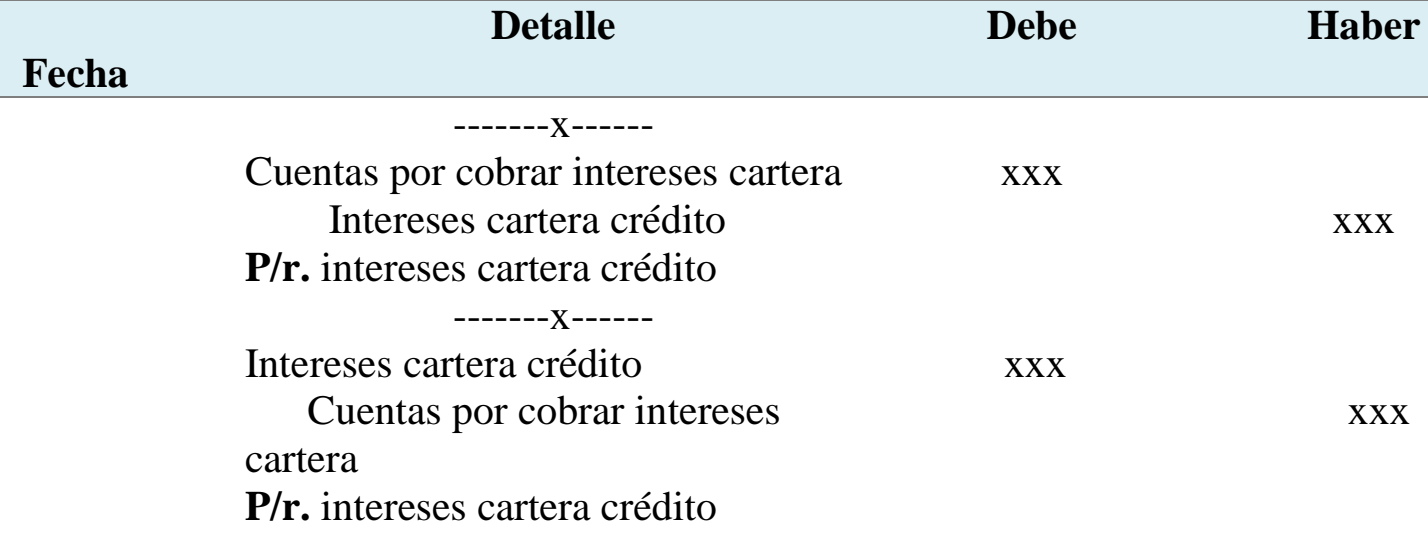

Dinámica

$\checkmark$ Se debita por el valor de las cuentas por cobrar.

$\checkmark$ Se acredita por el abono de cuotas de cuentas por pagar. 
ISSN: 2602-8506

www.visionariodigital.org

Vol. 3, N².1., p. 497-526, junio, 2019

Tabla 16. Propiedad, planta y equipo

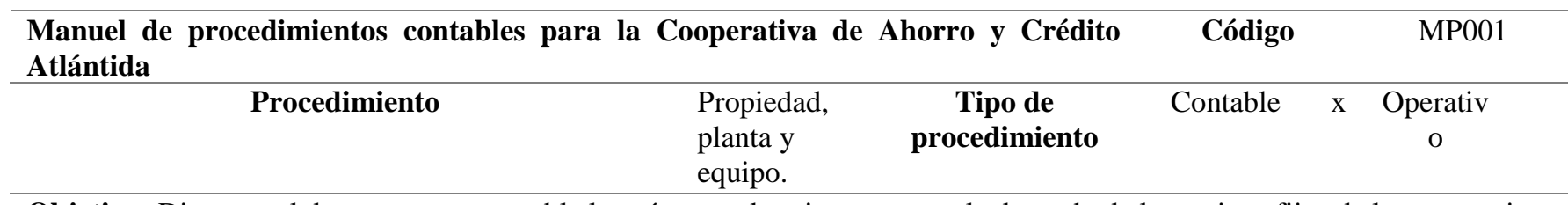

Objetivo: Disponer al departamento contable la guía para el registro y control adecuado de los activos fijos de la cooperativa.

\begin{tabular}{|c|c|c|c|c|}
\hline$\underset{\mathbf{N}}{\mathbf{N}}$ & Políticas & Procedimientos & Responsables & $\begin{array}{l}\text { Documentos de } \\
\text { referencia }\end{array}$ \\
\hline 1 & $\begin{array}{l}\text { El departamento administrativo y contable } \\
\text { serán los responsables de la adquisición de } \\
\text { activos fijos de acuerdo a la necesidad de la } \\
\text { cooperativa y su debida codificación. } \\
\text { Todos los activos fijos adquiridos por la } \\
\text { entidad serán entregados mediante acta- } \\
\text { recepción a sus empleados que estén a cargo } \\
\text { del manejo y protección de los activos. } \\
\text { La cooperativa tendrá el control de los activos } \\
\text { fijos mediante registros auxiliares clasificados } \\
\text { de acuerdo a su naturaleza. }\end{array}$ & $\begin{array}{l}\text { El gerente pedirá las debidas } \\
\text { cotizaciones para la } \\
\text { adquisición de los activos } \\
\text { fijos. } \\
\text { El gerente analizara } \\
\text { cotizaciones y tomara una } \\
\text { decisión. } \\
\text { Si a la decisión es favorable } \\
\text { se realizará el pedido de } \\
\text { compra del bien } \\
\text { El contador(a) receptara la } \\
\text { factura del bien para su } \\
\text { debido ingreso al sistema } \\
\text { contable. }\end{array}$ & $\begin{array}{l}\text { Gerente } \\
\text { Contador (a) }\end{array}$ & \\
\hline
\end{tabular}

Tabla 17. Depreciación propiedad, planta y equipo

Manuel de procedimientos contables para la Cooperativa de Ahorro y Crédito Código

Atlántida

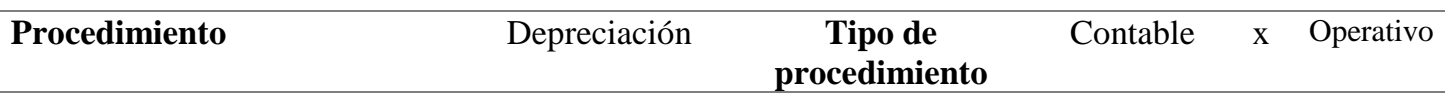

Objetivo: Facilitar al departamento contable las pautas para la depreciación de los activos fijos en la cooperativa.

\begin{tabular}{ccccccc}
\hline $\begin{array}{c}\text { N. } \\
\mathbf{0}\end{array}$ & Políticas & \multicolumn{2}{c}{ Procedimientos } & Responsables & $\begin{array}{c}\text { Documentos de } \\
\text { referencia }\end{array}$ \\
\hline 1 & La depreciación de los activos fijos se lo & El contador(a) & recibirá la & Contador (a) & Factura
\end{tabular}

efectuará a partir de la fecha en el cual el bien factura de adquisición de

entro en servicio.

activo fijo y procederá al

registro del bien.

La depreciación de los activos fijos se lo El contador(a) verificara si el efectuará a partir de la fecha en el cual el bien bien está en servicio.

entro en servicio.

Si ya está en servicio se
procederá a realizar su
respectiva depreciación de
acuerdo al porcentaje
establecido en la normativa.
Se realizará los cálculos y
registro contable de la
Depreciación diferenciando
por tipo de activo.


Tabla 18. Contabilización depreciación activo fijo

\begin{tabular}{llcc}
\hline \multicolumn{1}{c}{ Detalle } & Debe & Haber \\
\hline Fecha & \multicolumn{1}{c}{$\begin{array}{c}\text {------X----- } \\
\text { Gasto depreciación activos fijos }\end{array}$} & xxx \\
$\quad$ Depreciación Acu. Activos & & \\
fijos & P/r. Depreciación propiedad, planta & & \\
& y equipo.
\end{tabular}

\section{Conclusiones}

- Los manuales de procedimientos son la guía para el desempeño eficiente de las diferentes áreas en las cuales los empleados se manejan dentro de la organización, además de servir como medio de evaluación de la eficiencia y desempeño del personal; además los manuales facilitan la interpretación de políticas y actividades y sirven de ayuda a la sistematización de los diferentes procedimientos contables, coordinando el trabajo con las distintas áreas.

- El manual de procedimientos contables es un elemento que forma parte del proceso administrativo, así como también del control interno, el mismo que conlleva a que la empresa cuente con información precisa, oportuna, detallada, ordenada y completa; donde se visualice en forma exacta cada uno de los pasos, instrucciones, responsabilidades concernientes a las actividades de la empresa.

- El manual de procedimientos en una organización representa una guía práctica, donde se expresa, las políticas, procedimientos, controles; $y$, al disponer de este instrumento ayuda a disminuir los desaciertos tanto operativos como financieros, mostrando razonabilidad en los estados financieros; lo cual conduce a una toma de decisiones acertada.

- Las instituciones financieras del sector popular y solidario deben contar con manuales de procedimientos contables que viabilicen la elaboración y presentación de los diferentes estados financieros, garantizando una efectiva información contable, misma que producirá efectos positivos en el incremento de beneficios económicos y utilidades tanto para el talento humano como para la cooperativa. 


\section{Referencias Bibliográficas}

Álvarez Torres, Martin G (1996) Manual para elaborar manuales de políticas y procedimientos. México: Panorama.

Aguilar, A., \& Cabrale, D. (2010). Evaluación del sistema de control interno en la UBPC Yamaquelles. España: Eumed

Aguirre, J. (2008). Auditoría y Control Interno. Número 15. Editorial Cultural. España: Madrid

Gavilánez Chicaiza, A. (2012). Sistema de Control Interno como herramienta para el mejoramiento de la gestión administrativa aplicado a la 16 empresa INTROVE CIA LTDA. (Tesis inédita de pre grado). Universidad Central del Ecuador, Quito

Gómez, G. (2011). Auditoría de Control Interno.

Palma, J. (2010). Manual de Procedimiento

Saiduvis, C. B. (mayo de 2011). Manual de Procedimientos contables para la empresa "Servicios y Construcciones J.M.H, C.A". Obtenido de Universidad de Oriente Tesis de Grado, Cumaná, Venezuela.

Tesen Yanaqui, M. y Vásquez Vásquez, L. (2012). Evaluación de los procesos operativos para establecer las deficiencias y limitaciones en el sistema de control interno en el área de almacén de las empresas molineras en el departamento de Lambayeque - Propuestas de Mejora.Universidad Católica Santo Toribio de Mogrovejo, Chiclayo.

Gary Dessler Ricardo Varela (2016) Administración de Recursos Humanos enfoque latinoamericano, Pearson Quinta Edición, México

Carrazco Torres, (2014). Manuales de procedimientos y organización, así como apoyo en las diferentes actividades que se realizan en el área. Tesis para obtener el título de Ingeniero en Innovación y Desarrollo Empresarial. Querétaro: Universidad Tecnológica de Querétaro.

Barreto, J., y E. Teodomiro (2018). Análisis de los procesos y operaciones contables desarrolladas en la empresa. Lima: Soluciones Empresariales EIRL Trujillo. Universidad Peruana Unión.

Carvalho, J. A. Estado de resultados (2016). Procesos contables. Medellín: Universidad de Medellín.

Chiriboga Rosales, Luis Alberto (2014). Las cooperativas de ahorro y crédito en la economía popular y solidaria. Quito: Imprefepp. 
Corona Romero, Enrique, Virginia Bejarano Vázquez, y José Ramon González García (2015). Análisis de estados financieros individuales y consolidados. Madrid: Uned publicaciones.

Escalante, P. (2014). Auditoría Financiera: Una opción de ejercicio profesional independiente para el Contador Público. Actualidad Contable FACES, 17(28), 40-55. Obtenido de https://www.saber.ula.ve/bitstream/123456789/38758/3/articulo_3.pdf

Fierro Martínez, Ángel María, y Francy Milena Fierro Celis (2015). Contabilidad general con enfoque NIIF para pymes. Bogotá: Ecoe Ediciones.

Zapata Sánchez, Pedro. (2017) Contabilidad general. Colombia: Alfaomega Colombiana S.A. 


\section{PARA CITAR EL ARTÍCULO INDEXADO.}

Valdez Fajardo, W., Narváez Zurita, C., Ormaza Andrade, J., \& Erazo Álvarez, J. (2019). Procedimientos contables y su incidencia en la sistematización de la información de la Cooperativa de Ahorro y Crédito Atlántida de la ciudad de Cañar. Visionario Digital, 3(2.1.), 497-526. https://doi.org/10.33262/visionariodigital.v3i2.1.586

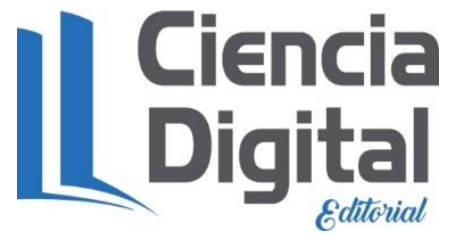

El artículo que se publica es de exclusiva responsabilidad de los autores y no necesariamente reflejan el pensamiento de la Revista Ciencia Digital.

El artículo queda en propiedad de la revista y, por tanto, su publicación parcial y/o total en otro medio tiene que ser autorizado por el director de la Revista Ciencia Digital.
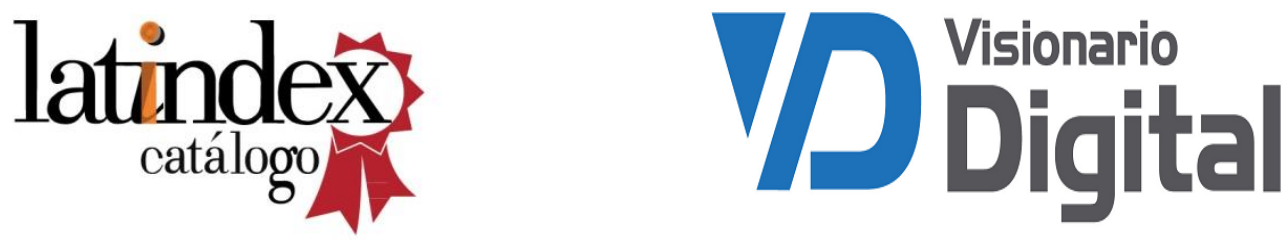